\title{
POST-EARTHQUAKE EVACUATION OF AGED CARE RESIDENTS FROM CANTERBURY, NEW ZEALAND: LESSONS IN RESILIENCE
}

\author{
Chrystal Jaye, Beatrice Hale, \& Sue Carswell
}

\begin{abstract}
In this paper we explore the relocation experiences of older people who were evacuated from damaged aged care facilities following a magnitude 6.3 earthquake on the 22nd February 2011 in Canterbury, New Zealand. Our analysis of older residents' and staffs' recollections of the chaotic aftermath of the earthquake and subsequent evacuation to host facilities in Dunedin shows that social capital in the form of social and community support plays a major role in the construction of resilience. This insight constitutes a highly pertinent contribution to both fields of disaster studies and the emergent literature on ageing and resilience. We used qualitative methods, with open-ended questions in semi-structured interviews of older people willing and able to discuss their experiences.
\end{abstract}

Keywords: disaster, aged care, resilience, evacuation, capital

\section{INTRODUCTION}

In this paper we explore the relocation experiences of older people who were evacuated from damaged aged care facilities in the disaster situation of the Canterbury, New Zealand, earthquake of 22nd February 2011. This earthquake resulted in the largest evacuation of residents from aged care facilities to date in New Zealand. Resilience in older people has previously been considered in theorising the transition to residential care, and the adjustment to the increasing frailty that accompanies the ageing process (Anstey et al. 2007, Lee 1999, Lee, Woo, and Mackenzie 2002, Milligan 2009, Nolan, Davies, and Brown 2006). Our contribution to the 'small but growing body of research on resilience and ageing' (Wiles, and Allen 2013, 141) is to show the importance of collective engagement and social capital in supporting resilience in the chaotic aftermath of a regional disaster. 
Elders have long been recognised as among the most vulnerable people in disaster events (Ardalan et al. 2010, Cloyd and Dyer 2010, Morrow 1999,). Of the approximately 1000 people who died as a result of Hurricane Katrina which devastated New Orleans in 2005, 71 per cent were over 60 years old, 47 per cent were over 75 years old, and a high proportion of the 250,000 left stranded in shelters were older residents (Klein and Nagal 2007, 56). Similarly, slightly more than 56 per cent of the estimated 13,000 fatalities in the earthquake and tsunami in Japan in 2011 were adults aged 65 years and older (Leoni 2012).

Earthquakes devastated parts of Christchurch, New Zealand's second largest city, and small towns in the Canterbury region during 2010 and 2011. The first major earthquake struck on the September 4th, 2010, causing significant damage, and prompting the evacuation of two aged care residential facilities. A second devastating earthquake occurred on February 22nd, 2011, in which 185 people lost their lives, and many buildings and the city's infrastructure received major damage. It is difficult to assess the impact of the February 22nd, 2011, Canterbury earthquake and consequent evacuation on the residents of aged care facilities. As Shenk et al. (2015) note, the vulnerability of older people varies significantly with age, health, family and economic circumstances.

As a result of the February 2011 earthquake seven residential facilities in Christchurch were fully evacuated and two were partially evacuated. This resulted in the loss of 516 aged care beds and a large number of retirement village units, representing approximately ten per cent of the local aged residential care population. Of those in subsidised residential care, 298 older people were evacuated out of Christchurch and 194 were relocated within the city (Heppenstall et al. 2013, 421).

The immediate challenges facing managers and staff at aged care facilities after the February 2011 earthquake included assessing the risks from damaged buildings, infrastructure, liquefaction and flooding (broken water and sewage pipes). They also had to ensure residents' safety. There were injuries and shock among both staff and residents within their facilities, and staffing disruptions because of the widespread damage to the city's road system. Due to limited telecommunications and power outage, staff and residents were uncertain about the wider scale of the event in the city, and were extremely concerned for the safety of their own families (Carswell 2011, 2).

The decision to partially or fully evacuate a residential facility was based on assessments of structural damage to buildings, and the impact of liquefaction and flooding in and around buildings. Some facility managers decided 
to evacuate immediately, while others evacuated over the following days and weeks. Evacuations were first managed locally and then by the National Coordination Centre following the declaration of a national emergency.

Facilities that evacuated immediately arranged for residents to be transported to other facilities in Christchurch. Organisations with multiple facilities were able to respond quickly. For example, one large corporate residential facility received 100 evacuees on the day of the earthquake (Carswell 2011, 22). This necessitated accommodating people as best they could in communal spaces and in rooms shared with others. Where practical, management and staff from the evacuating facility accompanied residents to their destination and stayed to assist with their care. This was not always possible when residents were evacuated beyond Canterbury, although some caregivers did accompany busloads of people to Dunedin

In those facilities that staged evacuation over the days immediately following the earthquake, all available staff, including managers and non-rostered staff, assisted alongside family members and volunteers. During the first night residents at these facilities slept in lounges and dining rooms on mattresses, settees and reclining chairs, and some 'double bunked' in safe rooms. The priorities for all facilities were that residents were safe, warm, hydrated, fed and had their medical needs attended to.

\section{THEORISING TRAUMA AND RESILIENCE}

Definitions of trauma encompass the notion of disasters as harmful events requiring extraordinary coping efforts (Meichenbaum 1994 cited in Graziano 2004, 5). Traumatic memories for the elderly as a generational cohort often include those of the widespread societal disasters of the twentieth century such as the major wars, and the Great Depression circa 1930s and 1940s. In addition there are accompanying personal traumas punctuating people's lifespans. Accidents, loss of income, bereavements, health and welfare problems are also characteristic of the traumas of this age group with their wealth of life experiences (Schnurr et al. 2002, Shenk et al. 2015).

Monat and Lazarus (1991 cited in Graziano 2004, 4) assert that traumatic stress occurs when demands 'tax or exceed the adaptive resources of an individual, social system, or tissue system'. A traumatic situation might result in a variety of symptoms including emotional detachment, constricted affect, feelings of helplessness, dissociation, substance abuse, and characterological and interpersonal problems Meichenbaum 1994 cited in Graziano 2004, (Terr 1991). 
Lantz and Buchalter $(2001,35)$ suggest that, 'feelings of anxiety, helplessness, hyperarousal and depression are common, as are recurrent thoughts about the new images and events'.

Adaptive responses to trauma constitute what a number of researchers describe as resilience models of coping (Agaibi and Wilson 2005, Benight and Bandura 2004, Wild, Wiles, and Allen 2013). Resilience is generally defined in terms of the process whereby strengths and resources mitigate the impact on individuals and communities of the negative outcomes of traumatic experiences (Nelson and St. Cyr 2015, 93). According to van Kessel $(2013,123)$, empirical research on older people is a relatively recent contribution to the broader field of resilience studies. She identifies two primary ways of defining resilience in the literature: ability and adversity. Ability refers to several indices peculiar to each individual such as personality and skills, as well as problem solving, acceptance, adaptability, and orientation to the future. Adversity has tended to be framed in terms of ongoing life experiences such as aging, illness experiences, and dying. For example, Young, Green, and Rogers (2008) suggest that adverse experiences can result in individuals incorporating internal traits, such as hardiness and high self-efficacy, that promote coping. According to Resnick (2008) positive adaptations in terms of taking charge, being positive about ageing, and a willingness to make the best of what is accessible are characteristic of resilience in ageing.

Post-traumatic resilience has been described in terms of behavioural adaptation to situational stress and a style of personality functioning (Agaibi and Wilson 2005, 196) that includes extraversion traits of high self-esteem, assertiveness, hardiness, flexibility, humour, internal locus of control, and cognitive feedback. Van Kessel $(2013,125)$ suggests that the impact on resilience of events such as war and disaster during a person's lifespan has thus far been underresearched although some scholars have proposed stage theories to explain the process by which resilience can be crafted (see for example, Cook-Cottone 2004). Shenk et al. $(2015,37)$ claim that older people tend to cope well with the emotional distress associated with disasters because of what they have learned from their previous life experiences.

The relationship between resilience, social support and community has attracted attention in recent studies (Resnick 2008, Wiles et al. 2012). Social supports include those that are tangible or intrinsic such as those that tend to material needs, and intangible or extrinsic supports that are emotional oriented (Shenk et al. 2015, 37). Resilience, noted Resnick (2008), provides individuals with the resources and skills to accept change, avoiding self-pity and depression, 
allowing one to focus on recovery and adaptation. She has developed themes of resilience that explore the individual's acceptance of changed situations and circumstances and decision-making capacity. The ability to make connections is important, and she exemplifies this as older adults developing friends in a care facility; not seeing crises as insurmountable problems; accepting changes as part of living; and, moving towards new goals. Similarly, Janssen, van Regenmortel, and Abma (2011) found that mediating factors that facilitate resilience include: coping strategies; empowering relationships; and, structural contextual factors such as social support and the availability of suitable care.

Wild, Wiles, and Allen $(2013,139)$ suggest that social or community resilience is gaining relevance 'against a backdrop of increasing anxiety about 'risk' in Western societies', with reference to Beck (1992), Giddens (1991) and Ganong and Coleman (2002). Wild, Wiles, and Allen (2013) discuss the terms 'community' and 'resilience' using a framework of 'assets' and 'capital', and review the significance of social capital. Davis, Cook and Cohen (2005 cited in Wild, Wiles, and Allen 2013, 141), emphasise the value of 'high levels of social capital', suggesting that a definition of community resilience, would include: 'highquality built environments: good access to culturally relevant social services: and, low levels of socio-economic stratification. The inclusion of 'high quality built environments' may reflect the values of affluent western perspectives. For analysing the stories told by residents and staff about their earthquake experiences, the constituents of: 'human capital' - knowledge, skills, health, physical ability; of 'social capital' - networks, affiliation, reciprocity, trust, mutual exchange; and of 'physical capital' - infrastructure, shelter, transport, water, sanitation and energy, are extremely useful.

As an illustration of the ways in which social capital impacts on post-disaster recovery, Aldrich (2012) observed that in the aftermath of a disaster, individuals with greater ties to their devastated communities of origin are more likely to return to these same communities and become involved in recovery planning. Similarly areas with higher levels of trust are better able to mobilise their residents to participate in rebuilding. Social capital is also evident in the resources and assistance provided by social networks and clubs to communities. An example of this in the aftermath of the Christchurch earthquakes was the mobilisation through social media of local university students into an organisation that became the Student Volunteer Army (http://www.ucsva. org/). This group spent many days assisting in the post-earthquake clean-up of liquefaction in Christchurch suburbs. According to Aldrich (2012), the impact of social capital on post-disaster recovery is measurable and significant; 
individuals with higher levels of solidarity and community orientation tend to have stronger recoveries post-disaster than those who are isolated.

\section{METHOD}

Because our aim was to explore the remembered experiences and reflections of residents and staff of aged residential care facilities evacuated following the February 22nd, 2011 earthquake, we decided that a qualitative methodology was most appropriate for this research. This methodology took the form of a semi-structured interview design, following the time-line of the earthquake, with open-ended questions that allowed for reflection on the part of the respondent such as: 'Please tell me what happened? What do you remember? How did you feel?'

There were two arms to this research, both conducted during the six months following the earthquake. The Dunedin arm was conducted by author Beatrice Hale, while the Canterbury arm was conducted by author Sue Carswell in conjunction with research commissioned by Eldernet, an information sharing organisation for older people. Ethical approval was gained from the University of Otago (11/002).

\section{In Dunedin}

Four aged residential care facilities approached their relocated residents on our behalf to ask if they were willing to be interviewed. This resulted in recruitment to the study of ten relocated residents, a group of six host residents (who requested they be interviewed after the project had begun), and eight care and activity staff. Further interviews were conducted with family members, either in their homes or by telephone. In addition, two local district health board officers who had oversight of the relocation in Dunedin agreed to be interviewed.

\section{In Christchurch}

As noted, the Canterbury arm of the study draws upon the work that Carswell conducted for Eldernet, on the aged care sector's response to the Canterbury earthquakes. This study included interviews with 105 managers and staff from 70 aged care organisations (of which five residential facilities were fully evacuated and two facilities that were partially evacuated); 14 stakeholders in key positions in the Canterbury District Health Board, Christchurch City Council/ Civil Defence Emergency Management, Age Concern, Help4U, Retirement Villages Association and Grey Power. Focus groups and interviews were con- 
ducted with 63 residents, including five residents who had been evacuated (Carswell 2011, 2012).

\section{ETHICAL CONSIDERATIONS}

At each participating host rest home, the process of interviewing was explained by the interviewers, and consent forms were signed. These interviews were taped, with the proviso that should the interviewee become distressed, the interview would be terminated, and referral made to a counsellor if necessary. It was explained that withdrawal at any stage was acceptable, and that no one should continue should they feel distressed and anxious. As it happened, none of the interviewees wished to withdraw.

The researchers were fully aware of the sensitivity required to conduct these interviews. Although the relocated residents indicated willingness to participate, the interviewers had some concerns about reviving the memories of the earthquake trauma, and other traumatic memories triggered by the earthquake. Therefore the structure and questioning was open ended, and designed carefully following concerns Robson (2001) highlighted in her research.

\section{ANALYSIS}

A thematic approach to analysis concordant with qualitative methods was utilised; a combination of the template organising framework (Crabtree and Miller 1999) and immersion crystallisation framework (Borkan 1999) proving particularly useful. Specifically, our evacuated participants told stories that were structured around the earthquake and the immediate aftermath, evacuation through several stages or journeys, their arrival at their destination and the settling in process. This structure provided an initial template for categorising the interview data. An in-depth examination of the data through immersion crystallisation techniques of engagement, intuitive reading and re-reading revealed the nuances in participant's stories. Triangulation of the material across both arms of the study proved to be invaluable in providing a more complete and complex picture.

\section{FINDINGS}

Residents' narratives tended to follow the time line of the earthquake, from the first shake to the evacuation, to arrival at the new facility and 'settling' in. The presentation of our findings follows the same timeline, first describing the immediate shock of the earthquake and then the events that followed. 
UPHEAVAL

Earthquakes subvert individuals' sense of reality and their known world. What was solid and immovable before the earthquake, the ground, after the earthquake becomes fluid, wavy, cracked open, and literally liquid in the case of liquefaction. There is no warning and continued aftershocks further erode environmental and personal security and stability. The ferocity of the earthquake left residents feeling 'numb'. Their responses portrayed a falling world where nothing was secure, not even the ground.

Well, you could say, the earthquake was reasonably large; you're sitting in a chair after lunch and things (falling) off the walls. It was incredible, and um, I don't know...it was just a big shock to everybody (Resident).

I was walking outside when I felt the quake. The quake shook and picked me up and I got thrown down on the ground. My walker fell on top of me (Resident).

According to Shenk et al. $(2015,37)$ older people have a tendency to resort to avoidance as a coping strategy in the aftermath of trauma which can account for reports of numbness following the earthquake. Certainly, the excerpts above reflect the very factual accounts of the earthquake given us by evacuated residents of the events that occurred.

In the aftermath of confusion, shock, stocktaking, and immediate concerns of rescue and safety, public spaces in facilities were transformed into temporary living arrangements. Residents described how they and the staff managed post-earthquake; sitting and sleeping together in one room, the corridor in one facility, the dining room in another. Staff placed recliner chairs and mattresses on the floors, avoiding risk areas such as the spaces below windows and chandeliers. As a result, norms of privacy and dignity were frequently compromised. Sleeping communally meant that residents overheard the prayers, dialogue, and vocalisations of other members of the group.

We were on the floor, on the floor for two nights; [a] couple [of people] were noisy, two women spoke all the time; one woman prayed all the time, "Father take me, Father take me" (Resident).

This excerpt also illustrates a commonly expressed sentiment of fatalism among resident participants. The average age of our participants was 80 years 
of age, and an acceptance of impending mortality might not be unexpected in this age group.

Managers of aged care facilities in Christchurch consistently reported that the majority of residents coped well with disruptions to utilities, sleeping arrangements and with frequent aftershocks. One manager said they were impressed by 'how resilient frail elderly are - they showed strength of character'. Many managers and staff talked about the importance of maintaining routines in order to minimise confusion and distress; one staff member emphasised that residents never 'missed a cup of tea' throughout the emergency period. Residents commented on the competency of the staff regarding emergency safety procedures.

They changed different areas where they wanted us to sleep. They didn't want us to go by the window. They taped all those windows up (Resident).

The excerpt above indicates that our participants did not take for granted the capacity of their facility and its staff to respond to the emergency situation of the earthquake. They were also aware that staff were concerned about the safety of their own families.

Our participants frequently drew on previous personal survival experiences to describe how they coped in the aftermath of the disaster. As others (Agaibi and Wilson 2005, Resnick 2008, Shenk et al. 2015, Wagnild and Young 1993) have noted, reserves of current resilience draw upon previous experiences. In the present research, the evacuees reminisced about other earthquakes they had survived in the past including the magnitude 7.1 earthquake in Canterbury on the 4th September 2010.

My Army training helped me get through, and I had experience of another quake situation as well (Resident).

Other comparable memories shared by this cohort included World War II and the Great Depression, widowhood and solo parenting: the excerpt above making reference to army training providing a skillset for coping with adverse circumstances. These memories were also frequently accompanied by a recall of past strategies for dealing with difficulties, such as a 'can do' and adaptive attitude, prayer, and humour, and constant affirmation of 'I can cope', a phrase frequently used. 
I lived through all sorts of ...I went through the war. I wanted to be a nurse...had been accepted by the hospital, then the war came, and I had to stop my own career and fit in. I had to deliver the milk round for my father, and with the war he became sick and he needed help, and I gave up my life to keep the home fires burning. So I just gave up any idea that I had [for a career] to help. Yes, the experience that you have....helps you get through things (Resident).

The above excerpt also illustrates poignant cultural and generational western mores: the expectations on children, and particularly daughters, in this cohort to put aside their own aspirations to care for elderly or infirm parents; and, an acceptance of the ways in which disasters can re-route a life trajectory. The following excerpt shows a resident reflecting on the meaning of past experiences of disasters, implying that traumatic events are predestined, and offer learning opportunities for the sufferer as well as a means of accruing moral capital.

Sometimes I feel these things are sent you know. I think probably, I often wonder if they're sent for a lesson... I often think everything we're going through is meant to be. I'm probably wrong, but thinking back... I think if you have good Scottish blood in you, you're inclined to attach a lot of importance to things like that (Resident).

\section{THE EVACUATION}

The context of the evacuations was extremely challenging and the difficulties with this process were reflected in the responses from residents, managers, staff and Canterbury District Health Board interviewees. Managers and staff from evacuated facilities identified a number of issues about evacuations organised by government agencies in relation to: the suitability of transport; timing and communication about where evacuees would be relocated; and, the process of informing families. There were also some innovative practices developed, and valuable learning about how to improve preparation for mass evacuation at all levels from individual care facilities, regional District Health Boards, and national emergency response (Carswell 2011, 2012).

Finding longer term placements for residents was challenging. Those with dementia had to be placed in an appropriate facility, while those with physical frailties were sent to other care homes that had the capacity to take them. Health officials organising the evacuation maintained the philosophy of evacuating as many residents as they could in one group from one facility to another, to maintain continuity, stability of relationships and familiarity with each other. 
That meant finding sometimes a dozen or more places in a receiving facility. The trauma teams in both Canterbury and Dunedin were placed on 24 hour shifts until these issues were resolved.

There were restrictions on what evacuees could take with them and also difficulties accessing possessions at some facilities due to earthquake and flood damage, and safety issues (Carswell 2011). In addition, the broken streets, liquefaction, and rubble rendered moving about the city very challenging and perilous amid the aftershocks. A variety of modes of transport were utilised to evacuate residents out of Christchurch, including aeroplane, bus and ambulance.

And the day we left, I said to the Manager, 'you realise I'll be taken away in an ambulance?' Because I had two heart attacks and two strokes. They got me an ambulance. I came down here in an ambulance. I knew very well that the likes of Air New Zealand, they would not fly a person like me (very immobile) down here in an aeroplane (Resident).

It was not a pleasant experience. Picked up, bundled up. We felt actually like cattle. There was no 'would you like to go there?' Put you in a bus. Everything taken out of your own hands and you're sort of herded... No 'would you like to go'? No questions. You're going to get sent somewhere else. If you don't like it put up with it. And that's how you had to...Thinking back, people don't like that much. People don't like it, they like to be masters of their own destiny (Resident).

In the confusion, some evacuated residents recalled that they did not know their destination. The sense of disempowerment was general: some families felt the same, with no or limited communication about where the older person was being sent, and, of course, for those living in Christchurch, having their own difficulties post-earthquake.

\section{ARRIVAL AND SETTLING IN}

Receiving facilities generally found the new residents were disoriented, and host staff had limited time to study accompanying documentation with up to ten exhausted older people arriving late at night.

That first night (I do the three to eleven shift) you could tell they were very nervous, and a lot of them were physically and mentally 
upset, and all they wanted to do was to talk, and someone to talk to, to be reassured that this was Dunedin and there wouldn't be an earthquake here. We can't say there won't be, but you're safe, and also a lot of them wanted to contact their families and let them know they were here and safe, and a lot of toll calls went through that night. It was mainly to reassure them, they're okay, let them know they were safe. You can sleep, it's fine (Staff member).

Residents arrived with medications, but with few clothes and without personal possessions. Some evacuees had been sitting in the provided wheelchairs for a long time, or sitting with slings underneath, and staff noticed sore bottoms and pressure sores which had to be dealt with as soon as possible.

To begin with a lot were in shock, and they were cold. They came at night, then were taken to their rooms, but they didn't like their rooms. It was hard to get to know them at first. You let them talk more and more, and they told us about their needs and we didn't have to probe too much. They were very forthcoming with their needs. I did expect them to be more upset. That came later it seems once they had settled in. Then the shock came out. Some became more and more withdrawn and we kept a special eye out for issues - and warning signs of depression (Staff member).

A couple of them, they were in their rooms and we knocked on their door and they jumped and said is there another earthquake coming. And it was just a knock on the door that did it. It was just little things like that that we actually really noticed (Staff member).

'Settling' for the night was part of the admission process and took a lot of time. Residents' comments gave a clear picture of the after-shock fatigue, fears, anxieties, and of coping with unfamiliarity. Depression is one of several negative psychological effects of disasters and Shenk et al. $(2015,37)$ note that the mental health needs of nursing facility evacuees are as important as their physical needs. Staff play a critical role in meeting these needs.

It was clear that many evacuees enjoyed the novelty of celebrity status in their host facility and emphasised the positive aspects of their evacuee status such as the support they received from Dunedin businesses, schools and community groups. 
The paper came and interviewed us, well me, really. People of Dunedin were very generous and gave us clothes. [Three local clothing retailers] all donated stuff, and because there were only three men, and 15 ladies, most of the gear we got was brand new. Even when we told the people we didn't need any more, the stuff kept on coming. And a school wrote to us. Every pupil in a class wrote to us, so we went out to the school and thanked them. It was really, really nice. People cared. A bus from here took us out, and two staff members saw to it. People are really great (Resident).

However, there were difficulties with integration into a new community. Certain similarities can be seen to the integration issues of refugees, for example, where Daley $(2009,167)$ reported that integration into a new community is a sensitive process. To begin with, the re-located residents kept together, defining themselves as newcomers. There was a strong attachment to each other within the visiting group, and perhaps extra loyalty to each other because of their shared earthquake experiences. The visitors were also anxious about their friends from the home facility who had been evacuated elsewhere. One older woman in her late eighties was moved again before the group had the opportunity to celebrate her birthday. She died shortly afterwards, near her family, but away from her friends.

Some of the host residents felt unhappy and excluded by the visiting evacuees, despite their perceptions of having offered friendship. 'Our new residents were friendly toward the staff but our residents here didn't quite know how to react and what to say, but they were friendly and concerned' (Staff member). Staff worked to promote cooperation and, where possible, active engagement and positive relationships between the host and visiting residents.

And it was interesting the old and new residents... It was a wee bit them and us to start off with, but then we did little things like at the tables in the dining room, and mixed up the residents' seating. To begin with it was the Christchurch table and the Dunedin table, but now we have the wee tables, and we've mixed them up, and they're all like one family now (Staff member).

Due to the ongoing lack of residential beds at aged care facilities in Christchurch it took some time for repatriation of evacuees. The success of the 'settling in' process clearly indicates a satisfactory integration of evacuees with their host facilities in Dunedin, but we do not know what happened to those residents who returned home to Christchurch. 


\section{DISCUSSION}

Interviews with relocated residents took place three to four months after the February 2011 earthquake. This time lapse was inevitable due to the processes of project planning and funding; however one consequence was that those affected had been able to process the events until the stories told and re-told became almost matter-of-fact. Ardalan et al.'s (2010, 2011) explorations of the aftermath of the 2003 Bam earthquake in Iran showed that memories of mental anguish and sadness caused considerable distress during interviews with survivors, with grief over the losses of family, destruction in the country, the loss of valued personal documents and memorabilia. We acknowledge that the scale of the Bam and Christchurch earthquakes were very different, with at least 26,000 lives lost in the former compared to 185 in the latter. While the responses in our own research may have lacked the immediacy of impact and emotionality of Ardalan et al.'s (2011), our participants' narratives nevertheless paint a compelling portrait of: the process of adaptation; decision making and action; and, caring and support amid chaos. We suggest that by the time we conducted our interviews, these older participants had assimilated their earthquake and evacuation experiences into their bank of life experiences as one more thread in life's rich tapestry.

In the aftermath of Hurricane Katrina, Cloyd and Dyer (2010, 503) observed that physical frailty, sensory and cognitive impairments sometimes resulted in decreased responsiveness of older people to public address and announcement systems as well as limited ability to access available services. In addition, they reported that even those elders considered robust could find that their physiologic reserves were insufficient to meet the response demands required of them in a disaster. Similarly, moving from familiar to unfamiliar surroundings could result in new behavioural problems or exacerbate existing ones for those who are demented or confused (Cloyd and Dyer 2010, 502). The trauma and stress of a natural disaster, added to the daily challenges of living with depression, can mean that older people with depression are less adaptable to new situations. Cloyd and Dyer $(2010,508)$ also warn of the necessity to be vigilant against elder abuse which was a problem in the aftermath of Hurricane Katrina. Our sample criteria excluded those with cognitive impairment, therefore our data did not include the earthquake perspectives or experiences of residents with confusion or dementia in addition to physical frailty.

One of the most significant strategies for resilience is that of agency and involvement in the decision-making process. The ability to exercise agency through involvement in the decision making process can ameliorate the dis- 
tress of leaving one's home and moving into care (Anstey et al. 2007, Lee 1999, Lee, Woo, and Mackenzie 2002, Milligan 2009). Aldrich $(2012,163)$ comments that participation in recovery and rebuilding of communities is critical in transforming victims into active agents with dignity. However, the agency of residents of aged residential care facilities was compromised in the aftermath of the earthquake. This may have reflected the scale of the event and the urgency of the situation which required decisions to be made quickly by managers and health officials to ensure the safety of residents and the continuation of adequate care. It may also be reflective of cultural paternalism towards older people in New Zealand society.

It is clear that relocated older residents drew on past disaster and wartime experiences for framing stoic responses to the aftermath of the earthquake (Agaibi and Wilson 2005, Resnick 2008, Shenk et al. 2015, Wagnild and Young 1993). Although evacuees were suffering the effects of exhaustion accompanied by physical and mental distress upon arrival after a prolonged transit, they also expressed gratitude and enthusiasm for the ways in which their host communities embraced them. This illustrates how positive perspectives contribute to the development of resilience following a disaster (Agaibi and Wilson 2005, 196).

Our findings illustrate the deployment of capital, in particular, components of human, social and physical capital. Our participants had low levels of human capital in the form of physical ability and health, but demonstrated high levels of human capital in the form of their ability to cope and 'make do'. Their ability was gained from prior individual and cohort experiences of adversity and disaster built up over their lifespan.

Physical capital includes infrastructure, shelter, transport, water, sanitation, and energy. It was clear that some aged residential care facilities had more physical capital than others. Facilities owned by national and international corporations exhibited far greater reserves of physical capital than did smaller locally owned facilities, evacuating residents to their own facilities within Christchurch and other centres. It was also evident that physical capital included the resources of facility staff and local communities when water tanks, generators and other equipment and materials were donated.

It is the impact of social capital that stands out in our findings as of primary importance in mitigating the potentially disastrous consequences of the earthquake. The shock of the earthquake and trauma of the post-earthquake chaos was shared by residents and staff alike. Social capital includes networks, reciprocity, trust and mutual exchange. Some residents' were able to utilise 
their own social capital and go stay with their own families. The staff of the aged residential care facilities were a key resource of social capital for other residents, mobilising members of their own families and communities to assist in the immediate chaotic aftermath. The continuing provision of care by careworkers and nursing staff to residents in the post-earthquake period extended well beyond routine expectations. High levels of trust, mutual respect and appreciation were evident in interview data. Sentiments of 'mucking in' are reminiscent of Turner's (1990) concept of communitas where shared liminality confers a sense of community characterised by the levelling of prior social distinctions and hierarchies.

The strategy of evacuating survivors from short term emergency shelter to long term accommodation can negatively impact the social capital of vulnerable individuals by removing them from their communities (Aldrich 2012, 174; Shenk et al. 2015, 40). Following evacuations after the 1995 Kobe earthquake, over 240 relocated survivors died 'lonely deaths' in their new apartments isolated from their friends and families and other social networks (Aldrich 2012, 174). The strategy employed by evacuation planners in the Christchurch situation of keeping groups from the same aged care facility together would have mitigated this happenstance, although as reported above, groups of evacuees were sometimes separated from each other.

Supporting Wild, Wiles, and Allen (2013), our research clearly shows a number of elements that contribute to constructing an environment of social resilience. This included staff at both ends of the re-location who 'went the extra mile' to help, and the enormous goodwill demonstrated by host staff and residents. The details of the process of this outreach are fascinating in the minute attention paid to friendship, care, and socialising. While the lessons identified from the evacuation process highlight how organisational responses can be improved to minimise trauma (Carswell 2011, 2012), the wider social community is also important in sustaining the efforts of service staff in supporting resilience in older evacuees. It would have been interesting to follow the relocated participants for longer to explore how they continued their status as visitors or whether they became 'settled'.

We caution that theories of resilience should not mask or minimise the struggle and disadvantages for older people living with chronic adversity. Mitchell and Harris $(2012,6)$ warn that resilience can be attractive to policymakers keen to cut social services because they might extrapolate from the ability of some people who cope with adversity and risk successfully, that everyone should be able to cope. 
Residents in the affected aged care facilities were tossed into chaos unexpectedly and without warning when the earthquake of February 22nd, 2011 struck. The loss of agency and autonomy reported by participants in decision-making processes during the consequent evacuation has some resonance with the commonly occurring experiences of older individuals who are admitted into care as a result of a fall, and experience the transition from home to care as all the more traumatic because it was unplanned. One important distinction is that the transition into aged residential care is an individual experience whereas the evacuation was a shared process in the sense that residents in any one facility experienced the disaster event as a collective group and were usually evacuated in their groups to a host facility.

We argue that any model of resilience must account for the social contexts of traumatised individuals. This broader model would acknowledge human capital and shared cohort experiences, social and community capital, emotional and psychological support such as sharing of stories, care support, active social involvement, and engagement in social activity. It would also encompass the understanding that others can be relied upon; that a kind word will encourage others; that shared experiences and stories assist with coming to terms with the aftermath of trauma and finding ways to understand what has happened.

\section{ACKNOWLEDGEMENTS}

We thank the University of Otago for funding this research through a University of Otago Research Grant, and Eldernet for allowing their project to be used as the Canterbury arm of our project. The financial sponsors played no role in the design, execution, analysis, interpretation of data or writing of the study. We also offer heartfelt thanks to the District Health Board staff who offered guidance on the project, and to the residents, staff and managers of aged residential care facilities who so generously gave their time and stories. We are very grateful for the feedback provided by attendees at a symposium of medical anthropologists in Auckland in November 2014 that contributed to the refinement of the final manuscript.

\section{REFERENCES}

Agaibi, Christine, and John Wilson. 2005. 'Trauma, PTSD, and Resilience: A Review of the Literature.' Trauma, Violence, \& Abuse 6(3):195-216. doi: 10.1177/1524838005277438. 
Aldrich, D. 2012. 'Social capital in post disaster recovery: towards a resilient and compassionate East Asian community.' In Economic and Welfare Impacts of Disasters in East Asia and Policy Responses, edited by Y. Sawada and S. Oum, 157-78. Jakarta: ERIA.

Anstey, K, C. von Sanden, K. Sargent-Cox, and Mary Luszcz. 2007. 'Prevalence and Risk Factors for Depression in a Longitudinal Population-Based Study including individuals in the Community and in Residential Care.' Journal of Geriatric Psychiatric 15 (6): 497-505.

Ardalan, Ali, Monir Mazaheri, Hani Mowafi, Michael Van Rooyen, Fariba Teimoori, and Reza Abbasi. 2011. 'Impact of the 26 December 2003 Bam Earthquake on Activities of Daily Living and Instrumental Activities of Daily Living of Older People.' Prehospital and Disaster Medicine 26 (02):99-108. doi:10.1017/S1049023X11000045.

Ardalan, Ali, Monir Mazaheri, Kourosh Holakouie Naieni, Mohsen Rezaie, Fariba Teimoori, and Farshad Pourmalek. 2010. 'Older people's needs following major disasters: a qualitative study of Iranian elders' experiences of the Bam earthquake.' Ageing \& Society 30 (01):11-23. doi:10.1017/So144686X09990122.

Beck, Ulrich. 1992. Risk Society: Towards a New Modernity. London: Sage Publications.

Benight, C., and A. Bandura. 2004. 'Social cognitive theory of posttraumatic recovery: the role of perceived self-efficacy.' Behaviour Resesearch Therapy 42 (10): 1129-48. doi: 10.1016/j.brat.2003.08.008.

Borkan, J. 1999. 'Immersion/Crystallisation.' In Doing Qualitative Research, edited by B. Crabtree and W. Miller, 179-94. London: Sage.

Carswell, S. 2011. 'What we have learned, report one: Aged care provider learning on responding to the February earthquake in Canterbury.' Accessed February 19, 2014.https://www.eldernet.co.nz/IM_Custom/ContentStore/ Assets/7/98/b45068e6b3f6d818odb28bo92133d87d/2011-07-31\%20Cant\%20 EQ\%2oResearch\%2oFINAL\%2o.pdf..

- 2012. 'What we have learned, report two: Aged care sector response to the Canterbury earthquakes - residents' perspectives and emergency assistance.' Accessed February 19, 2014.https://www.eldernet.co.nz/IM_Custom/ ContentStore/Assets/8/38/e4e547a94ea7a88ae48a6fcb97d46eda/2012-08\%20 
What\%2owe\%2ohave\%2olearnt\%202.pdf .

Cloyd, E., and C. Dyer. 2010. 'Catastrophic events and older adults.' Critical Care Nursing Clinics of North America 22 (4):501-13. doi: 10.1016/j. ccell.2010.10.003.

Cook-Cottone, Catherine. 2004. 'Childhood Posttraumatic Stress Disorder: Diagnosis, Treatment, and School Reintegration.' School Psychology Review $33(1): 127$.

Crabtree, B., and W. Miller. 1999. 'Using codes and code manuals: a template organising style of interpretation.' In Doing Qualitative Research, edited by B. Crabtree and W. Miller, 163-77. Thousand Oaks, CA: Sage.

Daley, Clare. 2009. 'Exploring community connections: community cohesion and refugee integration at a local level.' Community Development Journal 44 (2): 158-71. doi: 10.1093/cdj/bsmo26.

Ganong, Lawrence, and Marilyn Coleman. 2002. 'Family Resilience in Multiple Contexts.' Journal of Marriage and Family 64 (2):346-48. doi: 10.1111/j.17413737.2002.00346.x.

Giddens, A. 1991. Modernity and Self-Identity: Self and Society in the Late Modern Age. Cambridge: Polity Press.

Graziano, Roberta. 2004. 'Trauma and Aging.' Journal of Gerontological Social Work 40 (4):3-21. doi: 10.1300/Jo83v40no4_02.

Heppenstall, Claire, Tim Wilkinson, Carl Hanger, Michelle Dhanak, and Sally Keeling. 2013. 'Impacts of the emergency mass evacuation of the elderly from residential care facilities after the 2011 Christchurch earthquake.' Disaster Medicine and Public Health Preparedness 7 (04):419-23. doi:10.1017/ dmp.2013.47.

Janssen, B., T. van Regenmortel, and T. Abma. 2011. 'Identifying sources of strength: resilience from the perspective of older people receiving longterm community care.' European Journal of Ageing 8:145-56. doi: 10.1007/ s10433-011-0190-8.

Klein, K., and N. Nagal. 2007. 'Mass medical evacuation: Hurricane Katrina and nursing experiences at the New Orleans airport.' Disaster Management Re- 
sponse 5(2):56-61.

Lantz, M., and E. Buchalter. 2001. 'Posttraumatic stress. Helping older adults cope with tragedy'. Geriatrics 56 (12):35-6.

Lee, D. 1999. 'Transition to residential care: experiences of elderly Chinese people in Hong Kong.' Journal of Advanced Nursing 30 (5):1118-26.

Lee, D., J. Woo, and A. Mackenzie. 2002. 'A review of older people's experiences with residential care placement.' Journal of Advanced Nursing 37 (1):19-27.

Leoni, B. 2012. 'Japan quake took toll on women and elderly'. United Nations Office for Disaster Risk Reduction. Accessed 24 March. http://www.unisdr. org/archive/25598.

Milligan, C. 2009. There's No place Like Home: Place and Care in an Ageing Society. Farnham: Ashgate.

Mitchell, Tom, and Katie Harris. 2012. Resilience: A Risk Management Approach. London: Overseas Development Institute.

Morrow, Betty. 1999. 'Identifying and mapping community vulnerability.' Disasters 23 (1):1-18. doi: 10.1111/1467-7717.00102.

Nelson, Charles, and Kate St. Cyr. 2015. 'What is vicarious resilience?' In Vicarious Trauma and Disaster Mental Health: Understanding Risks and Promoting Resilience, edited by G. Quitangon and M. Evces, 93-5. New York: Routledge.

Nolan, Mike, Sue Davies, and Jayne Brown. 2006. 'Transitions in care homes: towards relationship冈centred care using the 'Senses Framework.' Quality in Ageing and Older Adults 7 (3):5-14. doi: 10.1108/14717794200600o15.

Resnick, B. 2008. 'Resilience in aging: the real experts.' Geriatric Nursing 29 (2): 85-6. doi: 10.1016/j.gerinurse.2008.01.003.

Robson, Elsbeth. 2001. 'Interviews worth the tears? Exploring dilemmas of research with young carers in Zimbabwe.' Ethics, Place \& Environment 4(2): 135-42. doi: 10.1080/713665943.

Schnurr, Paula, Avron Spiro III, Melanie Vielhauer, Marianne Findler, and Jessica Hamblen. 2002. 'Trauma in the lives of older men: findings from the 
Normative Aging Study.' Journal of Clinical Geropsychology 8 (3):175-87. doi: 10.1023/a: 1015992110544 .

Shenk, D., B. Ramos, K. Kalaw, and I. Tufan. 2015. 'History, memory, and disasters among older adults: a life course perspective.' Traumatology, 15 (4):35-43. doi: $10.1177 / 1534765609359729$.

Terr, Lenore. 1991. 'Childhood traumas: an outline and overview'. American Journal of Psychiatry 148 (1):10-20.

Turner, V. 1990. 'Liminality and community' In Culture and Society: Contemporary Debates, edited by J. Alexander and S. Seidman, 147-54. Cambridge: Cambridge University Press.

van Kessel, G. 2013. 'The ability of older people to overcome adversity: a review of the resilience concept.' Geriatric Nursing 34 (2):122-7. doi: 10.1016/j.gerinurse.2012.12.011.

Wagnild, G., and H. Young. 1993. 'Development and psychometric evaluation of the Resilience Scale.' Journal of Nursing Measurement 1(2):165-78.

Kirsty, Janine Wiles, and Ruth Allen. 2013. 'Resilience: thoughts on the value of the concept for critical gerontology' Ageing \& Society 33 (Special Issue 01):137-58. doi:10.1017/So144686X11001073.

Wiles, J., K. Wild, N. Kerse, and R. Allen. 2012. 'Resilience from the point of view of older people: “There's still life beyond a funny knee”. Social Science \& Medicine 74(3):416-24. doi: 10.1016/j.socscimed.2011.11.005.

Young, Alys, Lorraine Green, and Katherine Rogers. 2008. 'Resilience and deaf children: a literature review. Deafness \& Education International 10 (1): 4055. doi: 10.1002/dei.234. 